\title{
Utility of MRI as the primary imaging tool in hypertension
}

\author{
Amy E Burchell ${ }^{1,2^{*}}$, Laura E Ratcliffe ${ }^{1,3}$, Andreas Baumbach ${ }^{1,2}$, Angus K Nightingale ${ }^{1,3}$, Nathan Manghat ${ }^{1,4}$ \\ From 17th Annual SCMR Scientific Sessions \\ New Orleans, LA, USA. 16-19 January 2014
}

\section{Background}

In patients with early onset or drug resistant hypertension (HTN) exclusion of secondary causes with imaging and endocrine testing is recommended. Traditionally a combination of echocardiography, renal ultrasound and renal CT angiography are used to investigate patients. Magnetic resonance imaging (MRI) is the gold standard imaging modality for the quantification of cardiac volumes and masses, with the benefit of being non-invasive and non-ionising. MRI can sensitively screen for renal artery stenosis and accurately evaluate renal artery anatomy. This is of particular relevance in the age of interventional therapies for resistant hypertension such as renal denervation. We proposed that a single MRI visit could provide all the imaging required in the routine evaluation of patients with HTN.

\section{Methods}

Patients attending a specialist hypertension clinic with early onset $(<40$ years), drug resistant or challenging drug intolerant HTN underwent a Hypertension Protocol MRI scan assessing for secondary causes and target organ damage. This included a full cardiac MRI with late gadolinium enhancement, imaging of the kidneys and adrenals, and MR angiography (MRA) of the renal arteries, aorta and cerebral vessels. Data is presented as mean \pm SD.

\section{Results}

71 patients (36 male), aged $54 \pm 15$ years, had an office blood pressure of $177 \pm 28 / 98 \pm 16 \mathrm{mmHg}$ on $3.6 \pm 2$ (range $0-8$ ) antihypertensive medications. $78 \%$ of patients had left ventricular hypertrophy by left ventricular mass index $(94 \pm 26 \mathrm{~g} / \mathrm{m} 2)$; other pathological

${ }^{1}$ Cardiology, Bristol Heart Institute, Bristol, UK

Full list of author information is available at the end of the article findings are summarised in Table $1.21 \%$ had $\geq 1$ accessory renal artery with $80 \%$ of patients anatomically suitable for renal denervation by current European guidelines. Figure 1 shows an example of renal artery stenosis on an MRA reconstruction.

\section{Conclusions}

MRI is a safe and effective method of screening for secondary causes of HTN and could replace the combination of echocardiography, renal ultrasound and CT imaging. MRI could offer novel imaging strategies for risk stratifying patients with HTN via assessment of aortic distensibility, pulse wave velocity and cerebral blood flow. It provides additional information for patients being considered for renal denervation and is likely to

Table 1 Clinically relevant findings on the Hypertension Protocol MRI scans for this hypertensive cohort.

\begin{tabular}{ccc}
\hline $\begin{array}{c}\text { Possible secondary causes of } \\
\text { hypertension }\end{array}$ & $\begin{array}{c}\text { No. of } \\
\text { patients } \\
(\mathbf{n}=\mathbf{7 1})\end{array}$ & $\begin{array}{c}\text { Prevalence } \\
\text { (\%) }\end{array}$ \\
\hline Nil & 33 & 46 \\
\hline Renesity alone & 27 & 38 \\
\hline Adrenal mass & 5 & 7 \\
\hline Single hypoplastic kidney (renal coloboma \\
synd.) & 4 & 6 \\
\hline Multinodular goitre (normal TSH) & 1 & 1 \\
\hline Target organ damage & 1 & 18 \\
\hline Left ventricular hypertrophy & 55 & 11 \\
\hline Myocardial infarction & 8 & 9 \\
\hline Aortic dilatation & 6 & 6 \\
\hline Cerebral microaneurysm & 4 & 1 \\
\hline Splenic artery aneurysm & 1 & 1 \\
\hline Coeliac axis stenosis & & 18 \\
\hline
\end{tabular}




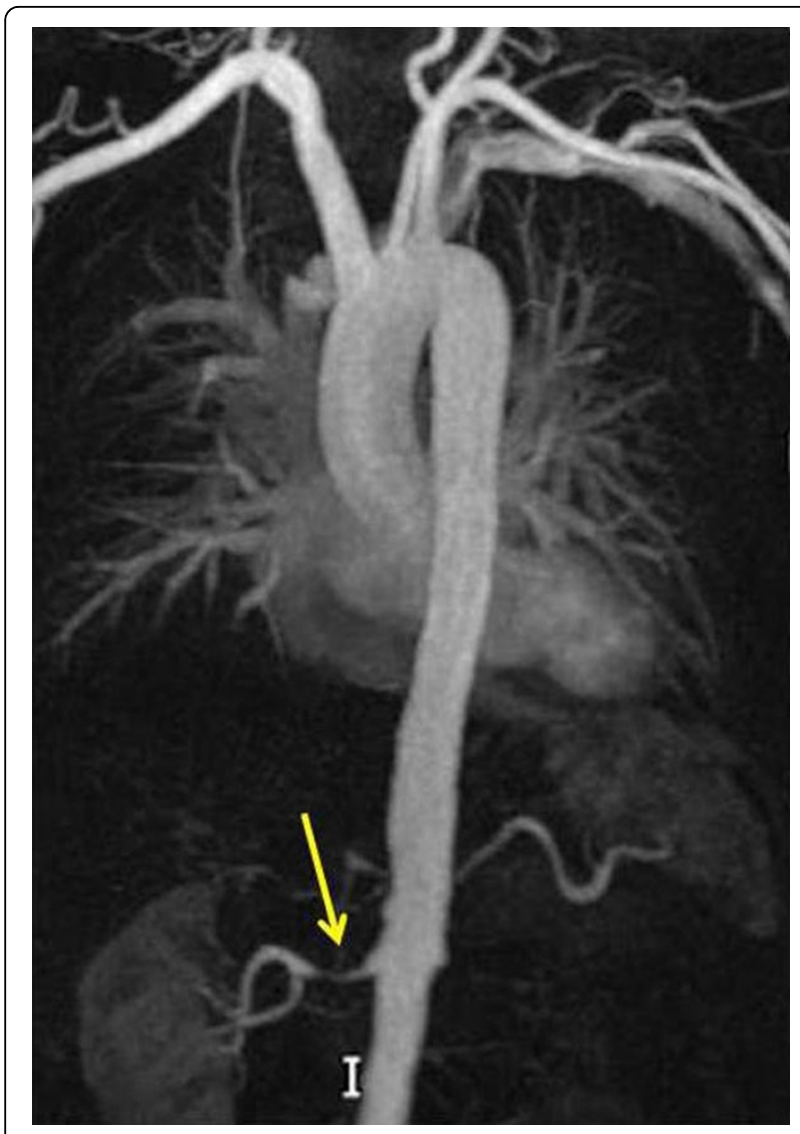

Figure 1 Right renal artery stenosis.

be a cost effective first line investigation for patients with possible secondary causes of hypertension.

\section{Funding}

Scans were performed as part routine assessment through an NHS funded Specialist Hypertension Clinic with additional support from the Bristol NIHR Biomedical Research Unit. Dr Burchell is funded by a University Hospitals Bristol NHS Trust Research Fellowship.

\section{Authors' details}

${ }^{1}$ Cardiology, Bristol Heart Institute, Bristol, UK. ${ }^{2}$ School of Clinical Sciences, University of Bristol, Bristol, UK. ${ }^{3}$ Physiology and Pharmacology, University of Bristol, Bristol, UK. ${ }^{4} \mathrm{NIHR}$ Biomedical Research Unit, University Hospitals Bristol NHS Foundation Trust, Bristol, UK.

Published: 16 January 2014

doi:10.1186/1532-429X-16-S1-P248

Cite this article as: Burchell et al:: Utility of MRI as the primary imaging tool in hypertension. Journal of Cardiovascular Magnetic Resonance 2014 16(Suppl 1):P248.

\section{Submit your next manuscript to BioMed Central} and take full advantage of:

- Convenient online submission

- Thorough peer review

- No space constraints or color figure charges

- Immediate publication on acceptance

- Inclusion in PubMed, CAS, Scopus and Google Scholar

- Research which is freely available for redistribution 